\title{
Low Back Pain: Not a Segmental Pathology
}

\author{
N. Rehan*1, Afzal Hussain ${ }^{2}$, Saleem Bashir ${ }^{3}$ and Huma Aslam ${ }^{4}$ \\ ${ }^{1}$ Chief Executive, Research Associates, Pakisthan \\ ${ }^{2}$ FCPS (Ortho) Chief KKT Consultant and Orthopaedic Surgeon \\ ${ }^{3}$ FCPS (Ortho) KKT Consultant and Orthopaedic Surgeon \\ ${ }^{4}$ MBBS KKT Research Coordinator
}

Received: October 19, 2017; Published: October 27, 2017

*Corresponding author: Dr. N. Rehan, Chief Executive, Research Associates, 291 / C, Askari - X Lahore, Pakisthan, Tel: 0300 843 9877 ;

Email: nrehan@yahoo.com

\begin{abstract}
Objective: To evaluate the pathologies of musculoskeletal system in patients complaining of low back pain.

Methodology: One hundred patients, who reported to us for treatment of Low back pain (LBP), were included in the study. All patients had radiological assessment of complete spinal cord as well as other segments of musculoskeletal system.

Results: There were 58 males and 42 females. The age of the patients ranged from 13 to 84 years. The mean age \pm SD was $52.5 \pm 15.9$ years. Nearly half of the patients (45\%) showed pathologies in neck region, 31\% in Temporo-mandibular joint, $22 \%$ in knees and $17 \%$ in shoulder joints. No pathology was noted among ribs or feet.

Conclusions: The results of the present study calls for wider dissemination of these findings and making health care providers of the importance of examining all area of musculoskeletal system when treating patients with low back pain.
\end{abstract}

\section{Introduction}

The system of muscles, tendons, ligaments, bones, joints and associated tissues that move the body and maintains its form is called Musculoskeletal System [1]. The diseases of this system, referred to as musculoskeletal diseases (MSDs), are extremely common and have important consequences for the individuals and society2. MSDs are one of the major causes of disease burden around the world and have been a significant reason for development of WHO's Bone and Joint Decade3. MSDs affect individuals by limiting their activities and restricting their participation in the work force, thus increasing the need for social support. Three MSDs, rheumatoid Arthritis, Osteoarthritis and Backache are important causes of Disability -adjusted - life years (DALYs) [2].

In World Health Organization Global Burden of Disease (WHOGBD) Study 2010, low back pain (LBP) was the leading cause of years lived with disability in the world, neck pain being the fourth cause, and other musculoskeletal disorders the fifth4. According to World Health Organization, the prevalence of MSDs is increasing in both developing and developed world [3-5]. In 2010 study, prevalence of low back pain based on 165 studies from 54 countries was $11.9 \pm 2 \%$, which increased to $12.2 \%(95 \% \mathrm{CI}=12.3-13.1 \%)$ in WHO's latest Global Burden of Diseases Study [5] of 2013.

Musculoskeletal conditions are a diverse group with regard to pathophysiology but are linked anatomically and by their association with pain and impaired physical function. They encompass a spectrum of conditions, from those of acute onset and short duration to lifelong disorders; including osteoarthritis, rheumatoid arthritis, osteoporosis, and low back pain. The prevalence of many of these conditions increases markedly with age, and many are affected by lifestyle factors, such as obesity and lack of physical activity [3]. New episodes are twice as common in people with a history of low back pain. Lifetime prevalence is58$84 \%$ and the point prevalence (proportion of population studied that are suffering back pain at a particular point of time) is $4-33 \% 9$ [6]. Low back pain affects men a little more than women and is most frequent in the working population with the highest incidence seen in those aged 25-64year [6]. The prevalence differs with the type of population studied. Three studies of Pakistan [7-9] show a prevalence of $6.5 \%$ to $44.1 \%$.

The exact source of acute low back pain is often difficult to identify. In fact, there are numerous possible pain producers including muscles, soft connective tissue, ligaments, joint capsules and cartilage, and blood vessels. These tissues may be pulled, strained, stretched or sprained. Additionally, annular tears (small tears that occur in the outer layer of the inter vertebral disc) can initiate severe pain. Even if the actual tissue damage is minor, and likely to repair quickly, the pain experienced may be quite severe. No matter which tissue is initially irritated, a cascade of events occurs 
which contributes to the pain experience. Numerous chemical substances are released in response to tissue irritation. These substances "stimulate" the surrounding pain sensitive nerve fibers, resulting in the sensation of pain. Some of these chemicals trigger the process of inflammation, or swelling, which also contributes to pain. The chemicals associated with this inflammatory process feedback more signals which perpetuate the process of swelling. The inflammation attributable to this cycle of events may persist for days to weeks [10].

Many studies have found patients with low back pain having significant changes in other joints [11-13]. However; this fact has never been brought to light in Pakistani literature. Since our centre primarily caters to the patients suffering from musculoskeletal disorders, it was thought worthwhile to undertake a similar study.

\section{Materials and Methods}

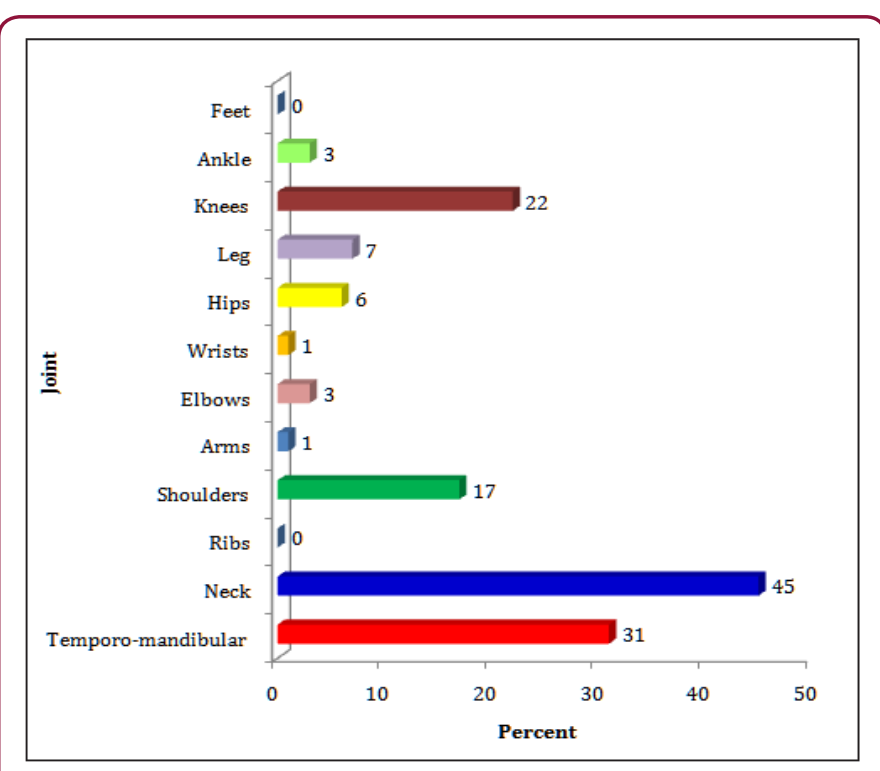

Figure 1: Joints involved.

One hundred consecutive patients complaining of low back pain were included in the study. There were 42 females and 58 male patients. On arrival at our centre, each patient was interviewed in detail by a Medical Officer / Psychologist. The presenting complaints were recorded and height, weight, Blood Pressure, Pulse and BMI are noted. Thereafter, the patient had complete physical examination by an Orthopedic Surgeon. For cervical spine, transverse processes are palpated on both sides from C2 to C6 for each vertebra and spinous process is palpated for $\mathrm{C} 7$ vertebra. For thoracic and lumbar spine, spinous processes are palpated for each vertebra. For sacral spine posterior surface is palpated. SI joint is palpated on posterior joint line, ankle joint is palpated on deltoid ligament and lateral collateral ligament, knee joint is palpated on site of attachment of medial collateral ligament, hip joint is palpated on greater trochanter, sternoclavicular and shoulder joints are palpated on anterior joint lines, elbow joint is palpated on lateral and medial side of olecranon, wrist joint is palpated on joint line dorsally and on radial and ulnar styloid processes and small joints of hands and feet are palpated on respective joint lines. Radiological and where needed laboratory investigations were undertaken for all joints shown in Figure 1. At our centre, all records are computerized. Radiological imaging is reported by local Radiologists as well as Radiologists at KKT Centre Canada.

\section{Results}

The age of the patients ranged from 13 to 84 years (Table 1). The mean age of100 patients was $52.2 \pm 15.9$ years being $51.9 \pm$ 17.8 years among males and $52.5 \pm 11.7$ years among females showing no significant difference $(\mathrm{P}=0.86)$. The pathologies seen in joints other than spine are shown in Figure-1. The maximum number of patients (45\%) showed pathologies in neck region, $31 \%$ in Temporo-mandibular joint, $22 \%$ in knees and $17 \%$ in shoulder joints. No pathology was noted among ribs or feet.

Table 1 : Demographics of Study Population.

\begin{tabular}{|c|c|c|c|c|c|c|}
\hline \multirow{2}{*}{$\begin{array}{c}\text { Age } \\
\text { (Years) }\end{array}$} & \multicolumn{2}{|c|}{ Males } & \multicolumn{2}{|c|}{ Females } & \multicolumn{2}{|c|}{ Total } \\
\hline & No. & Percent & No. & Percent & No. & Percent \\
\hline$\leq 25$ & 3 & 5.2 & 0 & 0 & 3 & 3.0 \\
\hline $26-50$ & 25 & 43.1 & 18 & 42.9 & 43 & 43.0 \\
\hline $51-75$ & 23 & 39.6 & 23 & 54.7 & 46 & 46.0 \\
\hline$\geq 76$ & 7 & 12.1 & 1 & 2.4 & 8 & 8.0 \\
\hline Total & 58 & 100.0 & 42 & 100.0 & 100 & 100.0 \\
\hline Range & $13-84$ & $26-76$ & $13-84$ & & & \\
\hline $\begin{array}{c}\text { Mean } \pm \\
\text { SD }\end{array}$ & \multicolumn{2}{|c|}{$51.9 \pm 17.8$} & \multicolumn{2}{|c|}{$52.5 \pm 11.7$} & \multicolumn{2}{|c|}{$52 . \pm 5 \pm 15.9$} \\
\hline
\end{tabular}

\section{Discussion}

Many investigators have studied the involvement of various joints in patients of low back pain. Shum et al11 of United Christian Hospital, Hong Kong studied 60 patients to examine differences in the kinematics and joint coordination of the lumbar spine and hips between healthy subjects and patients with sub-acute low back pain (LBP).They concluded that back pain was related to changes in the kinematics and coordination of the lumbar spine and hips during sit-to-stand and stand-to-sit. Assessment of back pain patients should include kinematic analysis of the hips as well as the spine.

In another study, the same group12 studied 20 asymptomatic subjects, 20 LBP and 20 patients with LBP and a positive straight leg raising test were requested to perform the sit-to-stand and stand-to-sit activities. Electromagnetic sensors were attached to the body to measure their kinematics. Back Pain patients exhibited compensatory movements and altered load sharing strategies during sit-to-stand and stand-to-sit activities. They conclude that the therapy should take account of these changes so that normal kinematic and kinetic characteristics of the spine and hip can be restored.

Rahbaret et al. [13] of Tabriz University of Medical Sciences in Iran conducted a case control study on 170 patients in order to evaluate the association between knee pain and lumbar disorders. They concluded that low back pain may be responsible in the development and/or progression of knee pain. Conversely, chronic and debilitating LBP can be due to the effects of knee pain and lower extremity impairments. 
Renkawitz et al. [14] from University of Regensburg, Germany conducted an experimental study on 82 individual in order to examine the relationship between Low Back Pain (LBP), neuromuscular imbalance, clinical symptoms, and trunk extension strength on two independent occasions. A direct relationship between LBP and neuromuscular imbalance was documented in individuals with LBP, whereas no significant imbalance was found in subject without LBP. However, our findings are in contrast to the prevailing practices in Pakistan. Most health care providers treat low back pain as a segmental pathology. The moment a patient with low back pain comes to a Health Care Provider; a General Practitioner or an Orthopedic Surgeon, the total attention of health care provider gets focused on to lumber/sacral spine. Radiological investigations of spine are started ignoring a thorough examination of other musculoskeletal areas. The results of the present study are in conformity with the findings of international studies mentioned above. Up to $45 \%$ of patients with low back pain were having pathologies of other musculoskeletal areas also.

\section{Conclusion}

The results of the present study calls for wider dissemination of these findings and making health care providers aware of the importance of examining all areas of musculoskeletal system when treating patients with low back pain.

\section{References}

1. Adams SB Overview of Musculoskeletal System. Merck Manual Whitehouse Station NJ USA. (2014).

2. Brooks PM (2006) The burden of musculoskeletal disease-a global perspective. Clin Rheumatol 25(6): 778 -781.

3. Woolf AD (2000) The bone and joint decade (2000-2010). Annals of Rheumatic Disease 59(2): 81-82.
4. Lim SS, Vos T, Flaxman AD (2012) A comparative risk assessment of burden of disease and injury attributable to 67 risk factors and risk factor clusters in 21 regions (1990-2010) a systematic analysis for the Global Burden of Disease Study Lancet 380(9859): 2224-2260.

5. Global Burden of Disease Study Collaborators. Global regional and national incidence prevalence and years lived with disability for 301 acute and chronic diseases and injuries in 188 countries (1990-2013): a systematic analysis for the Global Burden of Disease Study (2013). Geneva: World Health Organisation (2015). Lancet 389(9995): 743-800.

6. Woolf AD, P fleger B (2003) Burden of major musculoskeletal conditions. Bulletin of WHO 646-656.

7. Babur MN, Awan WA. Risk factors of LBP among rural \& urban areas of Pakistan. Interdisciplinary Journal of Contemporary Research in Business (2011).

8. Khan MY, Siddiqui MA (2005) Prevalence of LBP in computer users. Pak J Med Sci 21(2): 159-163.

9. Kashif M, Ain QU, Heera SA, et al. (2014) Prevalence of LBP in male factory workers of Nishat Mills limited, Sheikhupura, Pakistan. J Pharm Altern Med 3:13-16.

10. NASS. Acute Low Back Pain. Burr Ridge, ILl: North American Spine Society (2009).

11. Shum GL, Crosbie J,Lee RY (2005) Effect of low back pain on kinetics and joint coordination on the lumber spine and hip during sit-to-stand and stand to sit. Spine 30(17): $1998-2004$.

12. Shum GL, Crosbie J,Lee RY(2007) Three dimensional Kinetics of the lumber spine and hip in low back pain patients during sit- to- stand and stand-to-sit. Spine 32(7): E211-E219.

13. Rahbar M, Toopichizadeh V, Shimia M (2015) Association between knee pain and low back pain. JPMA 65(6): 626-631.

14. Rekawitz T, Boluki D, Grifka J (2006) The association of low back pain, neuromuscular imbalance and trunk extension strength in athletes. Spine J 6(6): 673-683.

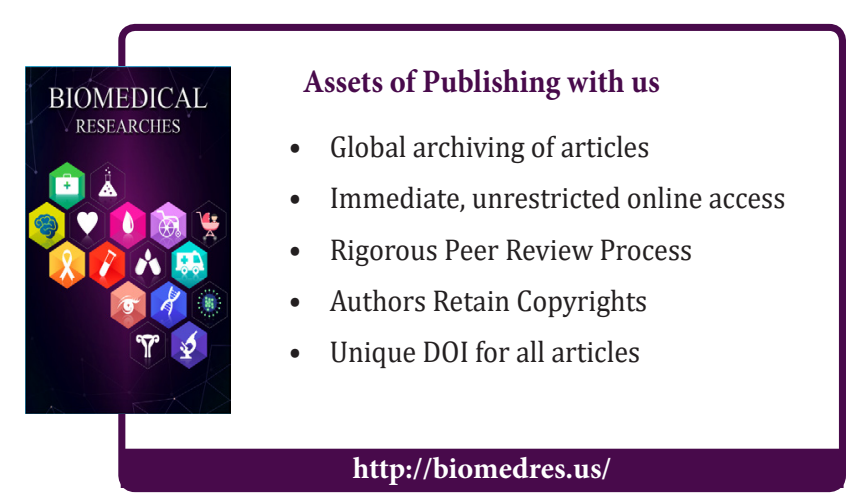

